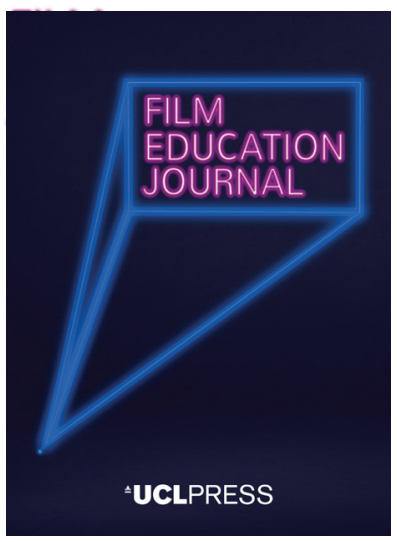

UCLPRESS

FILM EDUCATION JOURNAL

ISSN 2515-7086 (Online)

Journal homepage:

https://www.uclpress.co.uk/pages/film-education-journal

\title{
Cinema en curs: Transmission of film as creation and creation as experience
}

Núria Aidelman Feldman (iD) and Laia Colell Aparicio

\section{How to cite this article}

Aidelman Feldman, N. and Colell Aparicio, L. (2021) 'Cinema en curs: Transmission of film as creation and creation as experience'. Film Education Journal, 4 (1), 58-70. https://doi.org/10.14324/FEJ.04.1.05

Submission date: 18 September 2020

Acceptance date: 13 November 2020

Publication date: 10 June 2021

\section{Peer review}

This article has been peer-reviewed through the journal's standard double-blind peer review, where both the reviewers and authors are anonymized during review.

\section{Copyright}

(C) 2021 Aidelman Feldman and Colell Aparicio. This is an open-access article distributed under the terms of the Creative Commons Attribution Licence (CC BY) 4.0 https://creativecommons. org/licenses/by/4.0/, which permits unrestricted use, distribution and reproduction in any medium, provided the original authors and source are credited.

\section{Open access}

The Film Education Journal is a peer-reviewed open-access journal. 


\title{
Cinema en curs: Transmission of film as creation and creation as experience
}

\author{
Núria Aidelman Feldman* and Laia Colell Aparicio - A Bao A Qu, \\ Barcelona, Spain
}

First published in Toma Uno (Aidelman and Colell, 2012)

Translated from Spanish by María A. Vélez-Serna

\begin{abstract}
This article - initially published in Spanish by Toma Uno in 2012 - explores the Catalonian project Cinema en curs, an annual, recurring and now international programme of film education that takes place with students aged 10-18 in schools and colleges. First detailing both the rationale and methodology motivating the project, the article goes on to discuss core aspects of the approach of Cinema en curs: the Lumière minutes exercise and the short films which serve as the culmination of students' work on the project. In doing so, the article also explores the value of approaches to film education that help learners develop an appreciation of their own lived experiences and the places in which they live. A new introduction from the authors places the article's discussion of Cinema en curs in a contemporary context.
\end{abstract}

Keywords: place-based education, film-making, art education, Catalonia, Spain, realism

\section{Authors' note}

We first published this article in 2012, now almost a decade ago (Aidelman and Colell, 2012). Since then, Cinema en curs (Cinema in Course) has grown in various ways: the number of participants has increased, our methodology has developed, and the project has served as the basis for further initiatives and collaborations. At the time of writing, in 2021, we are developing the sixteenth edition of Cinema en curs, which is no longer limited to Catalunya, but is now also active in other Autonomous Communities (Galicia, Madrid, Euskadi, Andalusia and the Balearic Islands) and countries (Germany and Chile).

Over the years we have introduced new ideas, broadened our range of workshops, deepened our approach and generated new projects, while continuing to maintain the same pedagogical and cinematographic principles present at the inception of Cinema en curs. Indeed, it was one of our initial aims for the project to become a space for shared reflection between teachers and film-makers, what we consider an applied research lab. In this respect, analysing the processes, proposals and materials we offer as part of Cinema en curs has always been an essential part of the project. This ongoing work of shared experimentation and evaluation with teachers, film-makers and students has motivated many of the changes we have implemented in the project over the past nine years. These include: 
- In 2015, we changed the starting premise of the workshops. Rather than beginning with the Lumière minutes exercise described below, we now open workshops with the 'shots of the world' exercise. Inspired by film-makers such as David Perlov, Chantal Akerman and James Benning, students film their surroundings, rediscovering the places in which they live and go to school through cinema. Sometimes students choose to accompany their 'shots of the world' with short texts on placards or with voice-over. (Some of these films can be seen here: https://vimeopro.com/plansdelmon/shotsoftheworld.) While we still utilize the Lumière minutes exercise (examples of which can be seen here: http://cinemaencurs.org/en/films), this now takes place only in specific workshops.

- Students shoot their 'shots of the world' with mobile phones or simple home video cameras readily available to them. While other exercises and work will be performed using more professional equipment, starting with the students' own devices turns cinema into a possibility within reach, an everyday gesture that we feel is thus all the more valuable for them. In this respect, cinema is with us from the very first day of Cinema en curs, and it continues to be there within our lives at all times, for those who want it.

- Our workshops culminate in the completion of fiction films as outlined in the article below, and since 2012 we have expanded our approach to include documentaries. Whether fiction or documentary, the starting point for these final films reflects the same principles: we encourage students to portray a space, a people and collective memory as a means of highlighting their value. Cinema thus becomes not only a chance to get to know the places where participants live, but a means of developing a greater appreciation for them, and thus to feel more connected and committed to their environment. A selection of these fiction films and documentaries can be seen here: https://vimeopro.com/ cinemaencurs/cine-en-curso-seleccion.

Our project evaluation, and the conversations we have held with teachers and filmmakers, has encouraged us to start further new projects, developing out of Cinema en curs. These have included Photography in Course (http://fotografiaencurs.org/ca), which began with ideas and materials developed for Cinema en curs and aimed to reach a much larger number of schools, students and teachers; and the European programme Moving Cinema (http://movingcinema.eu/), as discussed in our previous publication in the Film Education Journal, 'Transmitting cinema: Some proposals for our time' (Aidelman and Colell, 2018).

We conclude by thanking Jamie Chambers for his invitation to publish an English translation of this article, and Teresa Arredondo for asking us to write the original Spanish version for Toma Uno.

\section{Translator's note}

Throughout this article, the word 'transmisión' has been rendered in different ways to account for nuances in meaning. In context, it expresses a communication of knowledge and skills in learning spaces, which is less direct than the English connotations of the word 'transmission' may suggest.

Cinema en curs (Cinema in Course) is a film pedagogy project with three main aims: (1) to enable children and young people's discovery of film; (2) to explore the pedagogical potential of film in schools and colleges; and (3) to develop methodologies 
and proposals for the dissemination of film and creativity. Cinema en curs brings forth both a pedagogy of film, and - simultaneously - a pedagogy with and through film. The project serves equally as a vote of confidence in cinema (and art, creativity and culture), and in education. The project began in Catalonia (Spain) in 2005-6, and its seven editions to date have brought together over two thousand students, twenty film professionals and eighty teachers. ${ }^{1}$

In the following article, we explain the development of the project and its pedagogical and cinematic principles, wherein a grounding in reality and lived experience is fundamental. We contend that film has such a vast pedagogical and artistic potential in large part because it allows us to know, think and explore the world in which we live. Film is a privileged form of knowledge and means of accessing reality, both near and distant, and these are some of the characteristics that make it a medium with such remarkably rich potential for education.

There are many ways to work with film in an educational context, just as there are many ways to understand film. In Cinema en curs, we understand cinema as art and as creation, always starting from the creative process. This is why we have prioritized an experience-based form of film education, drawing on both creation and spectatorship. This is one of the guiding premises for the project, which is structured in two main lines of work: the workshops with the students and the applied research lab.

The workshops take place in schools and colleges, during class time, and are taught jointly by a film professional and a team of teachers from a given educational institution. The workshops cater to students aged 10 to 18 , and take place across very different geographical and sociocultural contexts. They share a programme of screenings and practical activities, designed to allow students to analyse and enrich the ideas proposed. Practices, methodologies and materials are continually defined and developed on the basis of the experiences and evaluations arising from the workshops, and the collaborative work of the team. This is a further aim of Cinema en curs: to become a thought laboratory, generating proposals and methodologies for film dissemination that can be applicable to diverse contexts. This work has resulted in the online resource 'Making films' and the workshops 'Making films with Cinema en curs' and 'Petit Cinema en curs' ('Little Cinema en curs'), which started in 2010-11.

In what follows, we will attempt to summarize the principles and aims of Cinema en curs, its working methodology and the development of its workshops.

\section{Sharing film as art and creation as experience}

It is our belief that cinema must attract viewers who are able to enjoy it as an art form, viewers for whom a film is not simply a consumer product or pastime: in other words, cinephiles. In Cinema en curs, we approach film as a poetic act, in the sense of poiesis, the creative act. ${ }^{2}$ We therefore start with the appreciation of film, with the intention that students will enjoy it as they do painting, sculpture, architecture or literature. And - contrary to what some would have us believe - enjoyment also needs to be learnt. ${ }^{3}$

Like all other projects we have delivered through A Bao A Qu (www.abaoaqu. org), Cinema en curs approaches art as an experience - which overwhelms, amazes, moves and shocks us - rather than as 'content' - which is by definition limited and enclosed, hence controllable and measurable. Art is, and must continue being, a site for adventure.

There are some non-negotiable, essential characteristics of artistic creation, and indeed this is even more the case in an educational context. The creative process 
distinguishes art from any other activity, and makes it a unique way of knowing and relating to the world, oneself and others. This essential specificity of art makes artistic creation a key ally in the learning process. In Cinema en curs we believe that these aspects include:

- When creation is truly creative, it implies a fundamentally open process, and therefore uncertainty has an active role. In the case of the cinema we watch and make in Cinema en curs, this constant openness is even more radical, because cinema is an art made out of reality and, therefore, dependent on reality with its innumerable, uncontrollable variables. Teaching cinema as art and creation must be grounded in the present.

- There are no single answers in art. Right or wrong cannot be predetermined. Learning to watch and make films is not about assimilating a grammar made up of $A=B$ formulae, but about learning to look at the world, to explore and enjoy the resources and infinite expressive possibilities of cinema.

- It is important to get to know the tradition, the shared artistic heritage of cinema. And we should not approach this heritage as something dead and anchored in the past, which we must either venerate or overcome; we should approach it as something that nurtures our creative potential and our world view. Art makes the world wider, richer and more intense. Tradition enlivens and enriches the here and now. Artistic creation, and the enjoyment of work by great artists, transforms our perspective on reality, and therefore increases our ability to inhabit, comprehend, experience, enjoy and express our relationship with reality.

- Art cannot be consumed: it is neither a consumer product, nor a consumable good. A work of art (whether a novel, a poem, a painting or a film) is always and forever infinite and unbounded. Therefore, a true initiation into art must be through immersion. This fundamental and necessary task is the task of transmission. If we really believe in art, we need to believe in its power. Let us dare to expose learners to art! If we do so, art will make its mark.

- The most important thing is to want art, to allow it to be vital and part of life. Art cannot be simply something that is interesting or important to know. The value of art is its ability to transform our perspective, and therefore ourselves. Therefore, the teaching of art has to start with the essential and fundamental (founding) value of experience. Experience is not stored in some corner of memory, but it suffuses our way of being, our way of inhabiting the world.

If we truly consider these characteristics of artistic creation to be non-negotiable, then the methods for the transmission of art must abide by them. Most of all, we need to maintain the space for rigour and the high standards demanded by art - and by cinema, in the case of Cinema en curs. It is precisely because it takes place in school that the rigour inherent to cinematic creativity is key. In that sense, we share Elliot W. Eisner's (1972: 7) approach:

... the most important contributions of art are those that only art can provide, and that any art education program using art as an instrument to achieve other ends primarily is diluting the art experience, and in a sense, robbing the child of what art has to offer. ${ }^{4}$

Indeed, our years of experience with Cinema en curs have shown us that one of the wonders of cinema in schools is that cinematic rigour is directly proportional to pedagogical rigour. This premise also works for the watching of films. When we film, we aspire to bring out the best of our abilities, and when we select the films we will 
watch and discuss with students, we choose from among the greatest film-makers of all time.

Cinema en curs approaches the aim of conveying film-as-art through two standpoints: bringing film professionals (film-makers, cinematographers, screenwriters, editors) into the school, and developing a working method that links screenings and practice.

\section{Film professionals in schools}

During a year of Cinema en curs, film professionals are present in schools for 80 to 90 hours, across 25 to 30 workshop sessions with the students. Some workshops are two or three hours long, while others, particularly during shooting and editing, last a whole day. Film-makers always work alongside a team of teachers, and their continued and regular presence within the project is a key strategy for Cinema en curs. When we started the project, we were convinced that our aim of conveying cinema both as an art and as a craft was best left to the people who are dedicated to it. When working in parallel with a film professional who has momentarily stepped aside from their trade to go into a school or college, students discover not just a way of working, and of seeing and of relating to their surroundings, but also a personal relationship with film art: a way to understand and love it. Therefore, this dialogue between film-maker and students constitutes a prime opportunity to sharpen sensibilities. Beyond teaching students how to use a camera, sound equipment or editing software, the film professional can catalyse the discovery of a more expansive and acute sensibility towards their working materials, which are the materials of reality: light, colour, sound and movement.

\section{Linking screenings and practice}

The work of awaking an awareness and discovery of cinema in students is mobilized primarily through the links made between watching and practising. Watching films by great film-makers helps students understand certain essential aspects of cinematic art, and increases their desire to make their own films, their attention to creative choices, and their sensitivity to the constituent matters of reality. Students' horizons are thus broadened, ahead of the moment when they can take on the role of creator, making their own decisions, observing reality and inventing in each shot a way to frame it. It is not about imitating models, but rather about increasing perceptive ability, with the selected film fragments as inspirations. On the other hand, the direct practical experience of the creative process means that, increasingly, when students watch films, they can approach them with a film-maker's gaze, appreciating the artistic choices. Film education then becomes a two-way street: from screening to practice, from practice to screening.

The film clips used in the project are organized thematically in order to approach a central question of cinema, and to follow that central thread in order to work through key aspects of film creation in a transversal manner. Working from film clips in this manner allows students to pay close attention to film-makers' choices. We can focus on how each shot is composed, or look at editing or sound. Working with film clips can awaken for students an interest in the films that they might not have had were the films watched in their entirety, and may further foster the desire (always so valuable for learning) to watch the rest of the film so they can find out what happens.

Working with clips also facilitates an engagement with cinema history. This is another key aim for Cinema en curs: enabling students to discover great film-making 
from all periods and cultures. Throughout the course, students encounter film-makers such as Jean-Luc Godard, Hou Hsiao-hsien, Nicholas Ray, Jonas Mekas, Yasujirō Ozu, Roberto Rossellini, Abbas Kiarostami or Chantal Akerman. All clips are watched with subtitles. Further, every year the students attend a theatrical screening at the Filmoteca de Catalunya, since we also value the discovery of the enjoyment of watching films in ideal conditions in a cinema venue.

\section{Workshop structure}

The workshops are structured around four major stages, each corresponding to a creative practice: the Lumière minutes, the photography project or experimental film, the sequence, and the final film. Here we explore the first and last of these exercises in more detail.

\section{Stage 1: The Lumière minutes}

The workshops start with the Lumière minutes exercise. ${ }^{5}$ Lumière minutes are documentary shots lasting one minute exactly, and which are made in very specific conditions inspired by the frames shot by the Lumière brothers and their operators. The camera must be fixed on a tripod, no camera settings can be changed during the shot, and only one take is made.

The Lumière brothers filmed the world for the first time. They thus had to invent and discover everything, within their approach: subjects to film, the expressive potential of camera placement, the importance of the moment when the camera starts rolling. Langlois (Rohmer, 1968) and Labarthe (1998: 19-20) explain this clearly. The former, in his dialogue with Rohmer and Renoir, details the labour of observation, study, choice of angle and timing. The latter explains how the Lumière brothers had to film Workers Leaving the Factory more than once, studying and controlling action and timing in order to ensure that this first (and much repeated) film had both a fitting start and an end.

In inventing the cinematograph, the Lumière brothers invented cinema as well. In recovering parts of this first, primary experience of cinematic creation, the Lumière minutes exercise proposes a way of making films that is, above all, a way of looking at reality. Following in the Lumières' footsteps, this initiation into cinema also serves as a transformation of the gaze for students. After watching and discussing each of the selected Lumière views, each student makes their shot by choosing what and where they want to film, the framing and the precise start time. The Lumière views inspire creation, and the questions asked by those first film-makers now guide our work. The students' engagement with the films of the Lumière brothers is the first step towards cinematic creation (Figure 1).

The Lumière brothers filmed subjects from everyday life: workers leaving a factory, labour scenes, a dance and a game of bowls, streets and squares, the arrival of a train or the departure of a boat. The fascination that these films still hold today does not come from the spectacular or unique nature of the actions filmed, but from the way they were filmed.

These first shots of cinema history show the power of immediate reality, and especially the importance of knowing how to look at it. Thus, in the development of practice, this initial stage of the (re)discovery of reality is as important as the shoot. When they go looking for their Lumière minute, students look into spaces and corners they had never paid attention to, and stop to observe specific jobs or shops, already imagining possible framings. 


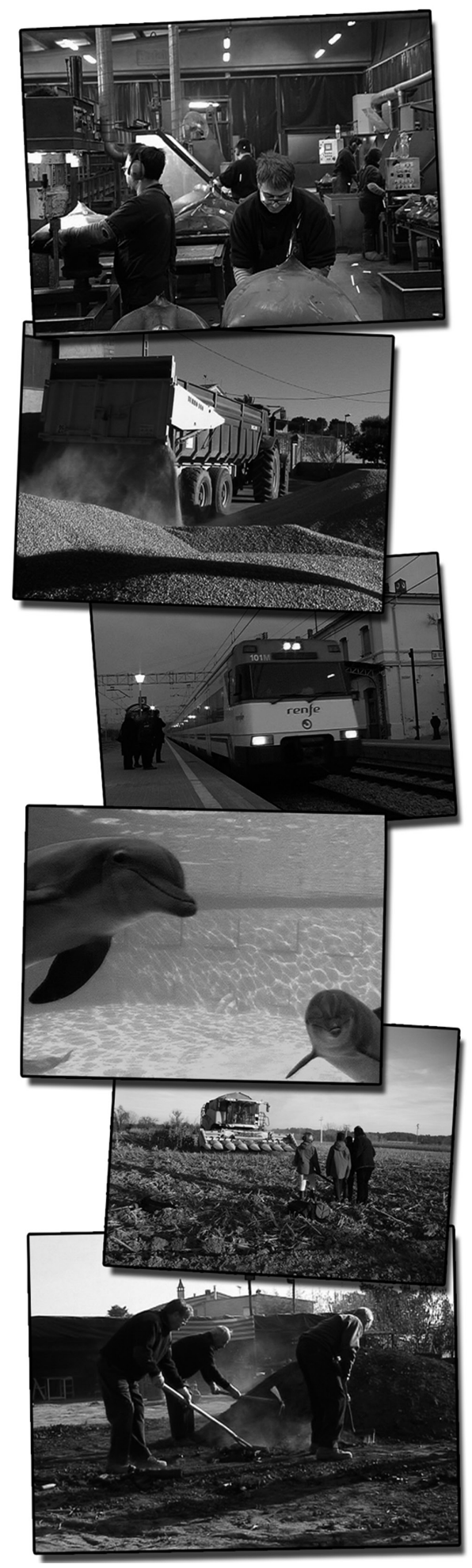

Figure 1: The Lumière minutes, 1-6 (source: author)

The arrival of a subway train and the choreographies that follow at any random station are revealed as a universe full of possibilities. The baker's daily labour becomes a precious pattern. The actions of grandparents in the kitchen garden, shoeing a horse or playing dominoes gain a whole new appreciation. Roads, squares and markets become vibrant spaces, full of movement and potential transformation. The world and 
our perspective on the world are transformed. This is the first key aspect of learning in Cinema en curs.

Once a subject has been chosen, each student must decide how to film it. In a documentary shot, the choice of framing is key in order to achieve the desired motion, in terms of the variations and transformations that animate the frame. Choosing how to film means constructing the world cinematically, organizing its forms, materials and actions.

The Lumière brothers were also masterful at framing, and there is much to learn from their perspective. Watching their films again, we pay attention not just to what is happening, but especially to what their choices were. In doing so, we discover that the Lumière brothers always located the camera with the distance, height and angle that best allowed them to capture a variety of movements, multiple visual planes and often surprising transformations throughout the shot.

The starting moment of the shot is just as important as the camera position. Just as the Lumière brothers did when shooting their 17 metres of film, students learn that, once they start recording, there is no way back. They can only attend to whatever happens during the minute of the shot.

In some of the Lumières' original films, the choice of that moment is the core of the film - arrivals or departures, movements into and out of the frame, beginnings and ends of actions. The choice of the starting point is made depending on the duration of the filmic subject, what will come into the frame during the shot, and also what will leave the frame. Here, students also need to observe and study the duration of actions, and their various transformations, in order to choose the most appropriate moment to start filming on the day of the shoot.

There is another key decision regarding when to film: the time of day. A location may be more or less busy depending on the time; there are things that only happen at particular times of day. This is also important with regard to the materials that cinema foregrounds: the light, its intensity and direction, and the colours and their variations over the hours.

The great cinematic and pedagogical power of the Lumière minutes resides in their simplicity and rigour. This is why it is important to maintain the rigidity of the initial conditions, and to communicate the importance of the choices and of the shoot itself. Being rigorous with cinematic modes of creation will allow the Lumière minute experience to bring into play several forms of learning beyond the cinematic.

\section{Stage 4: The final film}

The last few months of a year of Cinema en curs are dedicated to making a short film, between six and ten minutes long. The short film is the culmination, or capstone, of students' learning, and is thus partly the outcome of the preceding moments. It is intended to be a project that condenses and intensifies the rewards of filmmaking, which many of the students have already experienced during the previous exercises. However, it should also be understood as a new opportunity to get involved in collaborative group creation for those who, for any reason, are yet to have this experience. The final film has a very special character; it is 'the' group work, and the group need to make the most of it.

The short film must therefore be approached as a collective work, which requires the participation, effort and creativity of each member of the group. In contrast to what happens in professional film-making, when making films in school settings, we must make the film truly belong to everyone, to be the work of a collective auteur. The 


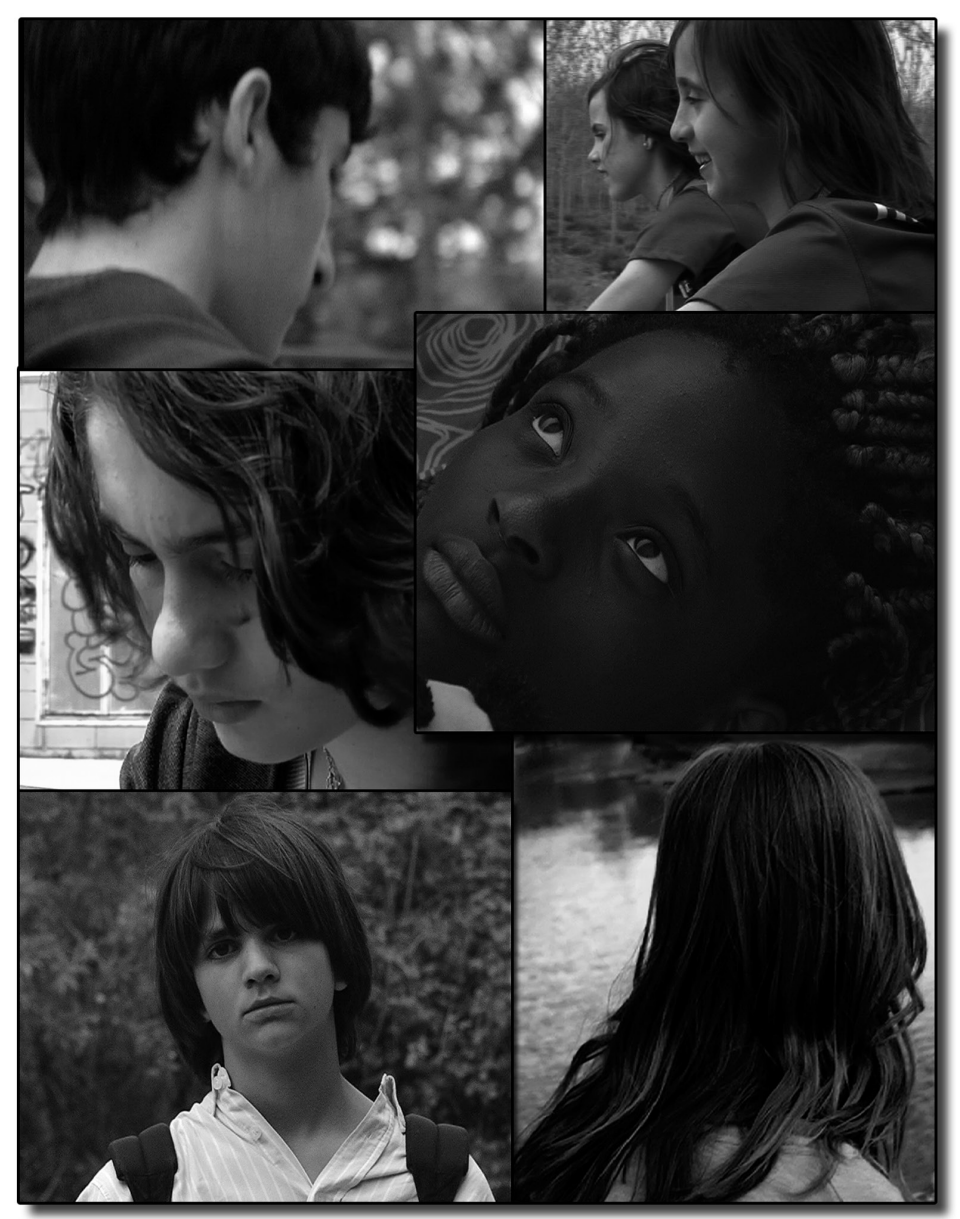

Figure 2: Clockwise from the top right corner: Camins, silencis i somriures (Paths, silences and smiles, Bordils School); Mirades que escolten (Listening looks, Mestre Morera School, Barcelona); Temps a venir (Times to come, Castellet Institute, Sant Vicenç de Castellet); Ciutat estranya (Strange city, Júlia Minguell Institute, Badalona); Escapada (Escapade, Els Xiprers School, Barcelona); L'última festa (The last party, Castell d'Estela Institute, Amer) (source: author)

screenplay is created together by all the students in the group, and during the shoot, students rotate through every craft. All students are involved in the editing, which is done in individual sequences and in small groups (Figure 2).

Writing a screenplay as a group is an extremely complex task, and it demands a great deal of time, effort and energy. In our experience it is worth it, however, not just because it allows a greater involvement for each and every student, but also because it provides many learning opportunities. In order to create this collective screenplay, we must start, however, by rejecting two tools that could potentially make the task easier: voting and what we would describe as an additive approach. In our experience, voting inevitably splits the group between winners and losers, with the screenplay only belonging to some. Additive work, by joining bits of various individual ideas, tends to lead to a disjointed screenplay, lacking in strength and emotion. The purpose during scriptwriting sessions is thus to pull on a thread that can bring forward shared ideas, and then to weave the story between all.

There are further fundamental preconditions for the final film, due to the particular approach Cinema en curs takes to cinema and the learning that it intends to bring into play. We seek to move away from fantasy, genre film, and stereotyped characters and 
situations. Instead, our starting point is the need to tell relatable stories, which happen to young people like the ones making the film, in the environments they know. In order to do this, we work again by rediscovering, revaluing and rearticulating the real milieu and lived experience within the school or college.

These starting points facilitate the screenwriting process, and allow us to develop the characters and emotions that are to take cinematic form. During the process of creating the film, and even more so once it is complete, the students discover that their own stories are also valuable, that the things that happen to them are important. Furthermore, they will see that what they have told and expressed through cinema can move others, and that cinema allows them to share their experiences and feelings.

The work of developing the film focuses on two key aspects: the characters and their emotions. Starting with the characters makes the ideas more real and embodied, and it facilitates a deeper work with emotions, which are central to any creative process. In Cinema en curs we are interested in a type of cinema where emotions are not conveyed through words or acting performance, but through cinematic means of expression. Emotions are expressed through the formal choices for each shot, and the collection of shots in a sequence. It is much easier, and more banal, to write on paper 'Anna is sad and says "I feel very lonely"', than to find a way to make that feeling pulsate in the shot. This requires having explored the emotion in depth, and explored cinema intimately, in order to find the cinematic form that expresses the character's feeling.

Another aspect worth mentioning here concerns the planning of the shots. A fundamental premise for the films we make in Cinema en curs is that each and every shot must be the outcome of a process of choosing each of the elements involved: framing, lighting, focus, movement, colour and so on. Each shot demands extreme attention. The final films made by students thus have no unnecessary shots; each shot is important and results from a serious reflection, which is - we should note - rather exceptional compared with many of the films we are used to watching in contemporary popular cinema. There is great cinematic intensity behind each shot, great attention both to film and to the world, and a great cinematic desire. While shooting, the whole group is completely focused on what unfolds, with attentive eyes and open gazes, watching the world.

\section{Shooting: An experience that binds}

For Cinema en curs, this is a state to which every creative practice must aspire: the moment of creation must be preserved as something exceptional and wonderful. In the Lumière minutes exercise, that emotional state is generated in part by the students' awareness that each of them will make their own 'minute', which is one of a kind in the world, and, in part, by the tension created by the single take. This gives the act of filming a weight and intensity that differs from those of the banal images we are used to seeing. When shooting the final film, the students have already experienced the unrepeatable value of each shot, and have thus felt the intensity of what happens only once: the wind in the trees, a look, the headlights shining in the distance. Rotating roles among the group also contributes to the unique and exceptional importance of each shot, as they are all considered equally important and valuable. Throughout the shoot, students will adopt all the roles (director, camera, script, sound recordist), sometimes only once.

The attention paid by students to each of the shots, to the world they are filming or listening to, and to how their classmates carry out an action, creates a particular kind of bond with cinema, with reality and with their classmates. It is a new and different 


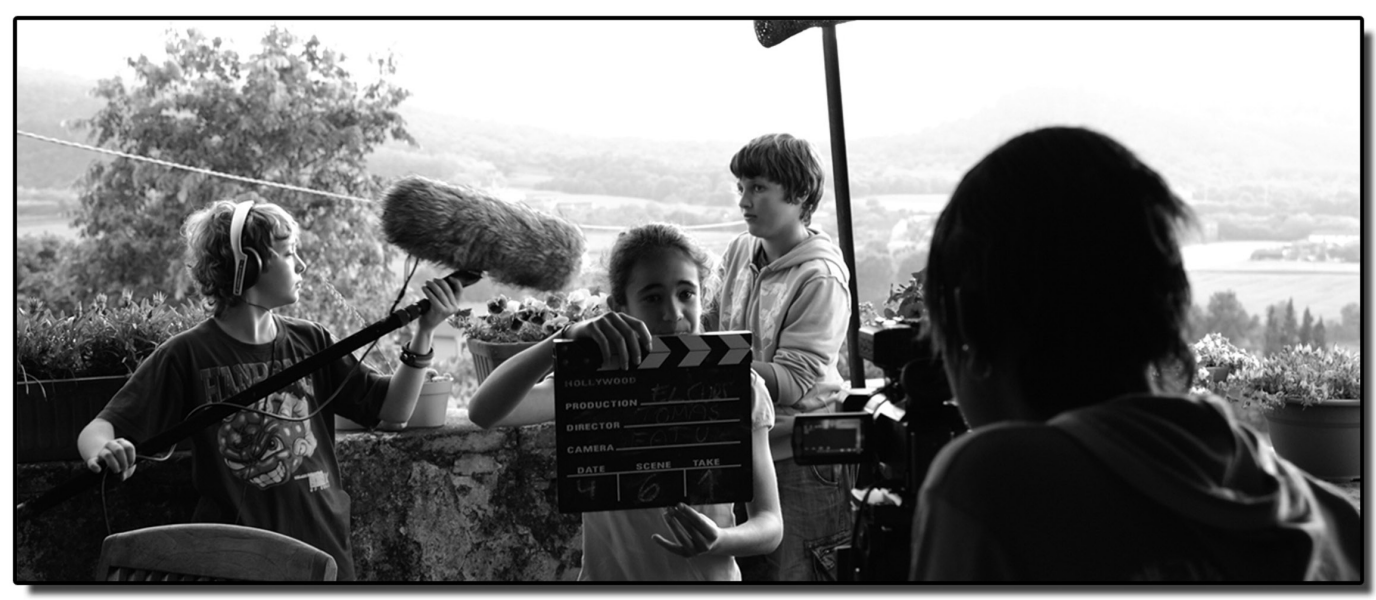

Figure 3: Students shooting their final film (source: author)

bond. True artistic creation, with its highlights and lulls, its longings, disappointments, surprises and desires, opens up and orientates us towards another experience, towards a life lived more intensely (Figure 3).

In this essay, we have noted some of the fundamental premises and methodological aspects we work with in Cinema en curs. As mentioned above, these reflect both cinematic and pedagogical principles. Here we feel that it is precisely the particularities and demands of cinematographic creation that makes it so rich pedagogically. We conclude by outlining some of the core aspects of this correspondence between cinematic and pedagogical values.

Cinema has an essential characteristic. Its raw material is the world: the spaces, things and people around us; light, colour and movement. When we make films, we have to pay special attention to our everyday surroundings, and we see them in a different way. We make films with our reality, with our familiar spaces, the light, buildings and trees that we see every day. This is why cinema is a binding process: it helps us rediscover and appreciate the reality near us, and we believe it therefore makes lives more liveable.

Because it is made out of reality, cinema is also an art of reliance. It relies on the crew (on each and every one doing their best work for each shot), and it also relies on how the light changes when a cloud passes, on the wind shaking the leaves, or on the birds that always seem to sing louder when the camera is rolling (because our attention is heightened). To rely means to attend, and be expectant; to be patient, to wait and sometimes to adapt.

Another of the pedagogical values of cinema is that it demands decisions. When we make a shot, we have to decide many things: how the action will unfold, where the camera is to be situated, light, focus, sound. There are infinite possibilities yet to be invented, and each person must find their own way of creating. It is not about knowing or guessing the right answer, but about choosing - about feeling the desire to shoot a take in a particular way. For some students, deciding and choosing is the hardest thing; unfortunately, school rarely or never presents them with that situation. This is why we must make the most out of the fact that cinema confronts them with the need to make choices, and does so by appealing to the individual sensibilities of each student.

This appeal to subjectivity is also tethered to a demanding expectation. The processes of cinematographic creation are long, and take plenty of time and effort. One needs to decide what and how to film, find the place that matches the frame we 
have chosen, focus, and then often repeat for several takes. Afterwards, in editing, we will watch over and over, decide again, try to correct, demanding the right cut. In our experience, nobody is as demanding as the students themselves. They frequently do eleven takes of the same shot until they are satisfied, and when they are editing they pay extremely close attention to each frame. This has shown us that rigour and effort are not imposed from outside; it is the project itself, and the students' own expectations, that fuel this work and make it possible.

Another key aspect of film-making is teamwork - not a team that works as the sum of its parts, but a true organism that requires almost perfect coordination. There must be a common goal, truly shared, and here collective commitment is as important as individual responsibility. A film crew depends on each and every one involved, as one person cannot cover for another person's work. At the same time, film-making requires a range of skills so diverse, and so different from school subjects, that every student can find their place and become important to the group. It is therefore a privileged chance to reinforce the self-esteem of those students who do not stand out in other school contexts, to transform group relations, and to give new opportunities to those who habitually do not have many.

These values are easy to recognize and explain, such as the need to share, pay attention, wait, choose, rely or trust, but they are not always easy to implement at school. If we believe that schools must encourage rigour and attention; help students love and inhabit their world; discover art and creativity; get to know themselves and others; invest time, and understand that things take time; generate expectations that can motivate the desire to learn; allow all students to know that they are able to do things well, that they all have talents and abilities, that work and dedication are meaningful, and that they have stories to tell: then we can think that cinema can and should play an important role in the education of children and young people. If we believe that cinema needs to be discovered and valued as art and creation, then we can think that its transmission in an educational context can, and should, be crucial to its future.

For more information see www.cinemaencurs.org/ or www.abaoaqu.org/.

\section{Notes on the contributors}

Núria Aidelman Feldman teaches photography and film at Universitat Pompeu Fabra, Barcelona, Spain, and is a member of the 'Cinema' group. She co-edited Jean-Luc Godard: Pensar entre imágenes, and she has contributed to several edited collections (Plossu Cinéma; Jean-Luc Godard: Documents; Erice-Kiarostami: Correspondencias). With Gonzalo de Lucas, she directed the short film Lai (2005), which has been screened at various festivals.

Laia Colell Aparicio has a humanities degree from Universitat Pompeu Fabra (UPF), Barcelona, Spain, where she obtained an advanced studies degree after receiving a scholarship to research Simone Weil's Cahiers in Paris. She has translated several film and philosophy books, and she is part of the UPF Institute of Culture's Research Group 'Bibliotheca Mystica et Philosophica Alois M. Haas'.

Together, Núria Aidelman Feldman and Laia Colell Aparicio lead A Bao A Qu, an association devoted to the design and delivery of pedagogical activities related to artistic creation. Their projects include Cinema en curs and Creadores en residencia en los institutos de Barcelona (Creatives in residence in Barcelona colleges). They also 
collaborate with institutions such as the Centre for Contemporary Culture in Barcelona, and MACBA (the Museum of Contemporary Art in Barcelona).

\section{Notes}

1. At the moment, some workshops are taking place in other autonomous regions of Spain, and a proposal is being developed to initiate the project in other countries, including Argentina.

2. In this sense, José Ángel Valente's 1957 article 'Conocimiento y comunicación' (Knowledge and communication) is relevant (in Valente, 1971: 3-10).

3. Alain Bergala (2007) has written on this topic.

4. In the original article, this is quoted from the 2005 Spanish translation.

5. This practice was designed in 1995 by the team behind Le Cinéma, cent ans de jeunesse, at the Cinématèque Française, as part of the centenary of cinema celebrations. Cinema en curs is closely associated with the French effort, working in collaboration, and sharing the yearly topic and some of the practices.

\section{References}

Aidelman, N. and Colell, L. (2012) 'Cine en curso: La transmisión del cine como creación y la creación como experiencia'. Toma Uno, 1, 231-42. Accessed 8 February 2021. www.cinemaencurs.org/ sites/default/files/communication_repercussion/files/toma_uno.pdf.

Aidelman, N. and Colell, L. (2018) 'Transmitting cinema: Some proposals for our time'. Film Education Journal, 1 (2), 147-62. https://doi.org/10.18546/FEJ.01.2.04.

Bergala, A. (2007) La hipótesis del cine. Barcelona: Laertes.

Eisner, E.W. (1972) Educating Artistic Vision. New York: Macmillan.

Labarthe, A.S. (1998) 'Des images qui nous regardent, entretien avec André S. Labarthe, par Jean-Louis Comolli'. Images documentaires, 31, 11-26. Accessed 15 March 2021. www.imagesdocumentaires.fr/lMG/pdf/ldoc31.pdf.

Rohmer, E. (1968) Louis Lumière/conversation avec Langlois et Renoir. Film. Accessed 16 March 2021. www.youtube.com/watch?v=uy3adCkeYh4.

Valente, J.Á. (1971) Las palabras de la tribu. Madrid: Siglo Veintiuno de España Editores. 